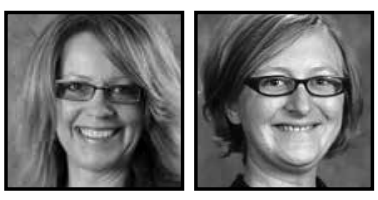

\title{
Utilizing Retrospective Miscue Analysis Strategies With Fifth Grade Readers: Focus on Comprehension
}

\author{
Linda Haling and Rebecca Spears, Illinois State University
}

\begin{abstract}
The purpose of this action research endeavor was to change the culture of an accuracy view of reading to one of comprehension in a fifth grade classroom. The goal was to establish a common vocabulary and to revalue the process of reading. A constant comparative method of data analysis was used throughout the study to observe changes in students' view of reading and use of miscue vocabulary. By the end of this study, students actively monitored comprehension, rather than trying to produce an oral reading event with $100 \%$ word accuracy.
\end{abstract}

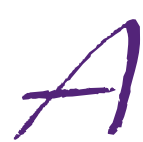

$s$ reading instruction is continuously pushed to the forefront of American education systems, teachers are often confronted with a contradiction between what they believe to be the most valuable aspect of reading and the assessment tools they use to determine reading ability. Many school districts, including Rebecca's, have shuffled through the maze of finding a reading assessment system that efficiently determines the instructional reading level of all learners in a classroom. However, many of the assessment systems that inevitably become adopted by countless school districts weigh the accuracy and speed of students' reading as the foremost indicators of a child's reading ability. While fulfilling a mandate from her school district to find the instructional and independent reading levels of each of her fifth grade students utilizing the Fountas and Pinnell Benchmarking System (2011), Rebecca became interested in investigating the importance of analyzing students' miscues more closely. She was being told to interpret her students' scores from this assessment in a way that explicitly followed the criteria for benchmarking levels as 
outlined by the publishers. Little room was left for her input as a teacher and her own professional judgment in the placement of her students on her school's "Data Wall."

Rebecca had always felt uneasy about determining a student's reading level or reading ability based on one assessment system and the method of implementation of this system in her district. When she learned more about miscue analysis and retrospective miscue analysis from Linda, she realized that accuracy models do not provide enough information about a reader to help inform instruction. Accuracy models also seem to devalue those reading behaviors that we want to develop in students. Therefore, our ongoing discussions led us to more systematically observe Rebecca's classroom through an action research process. The purpose of the study was to help Rebecca learn how to value her students' reading behaviors and help her students learn how to revalue themselves (Goodman, 1996). Specifically, the study addressed how varied and ongoing assessments might shift the culture and conversations in the classroom from one largely focused on accuracy to one focused on meaning.

\section{Situating Models of Assessment}

The accuracy of a student's oral reading ability is usually formally assessed during a timed oral reading of text that is specifically designed for assessment purposes (Theurer, 2011). During these assessments, the teacher marks an error when the reader's response (what the child says) is different from the expected response (what is in the printed text). The teacher then determines the student's reading level by calculating the percentage of errors the student made. In this assessment model, errors are weighed equally and do not take into account whether or not the error was meaningful.

Under most guidelines, all miscues carry equal weight, whether the miscue changes the meaning of the text significantly (e.g., substituting sentences for scents), moderately (e.g., substituting desserts for doughnuts), very little (e.g., substituting the for a), or not at all (e.g., substituting mommy for mom) (Halladay, 2012, p. 57)

Betts (1946) published accuracy guidelines for determining independent, instructional, and frustration reading levels. His scales posit that independent reading levels are met when a student performs an oral reading event with at least $99 \%$ accuracy. Instructional levels are met when a student reads aloud with between $95 \%$ and $99 \%$ word accuracy. Ideas about using percentages of word accuracy in oral reading to assign students' reading levels have not changed in recent years. The Fountas and Pinnell Benchmark 
Assessment System (2011) (BAS), for example, uses the following criteria for assigning reading levels for intermediate and middle grade readers (Levels L-Z, Grades 3-8):

- Independent: $98-100 \%$ word accuracy with 70-100\% comprehension

- Instructional: $95-97 \%$ word accuracy with $70-100 \%$ comprehension, or $98-100 \%$ word accuracy with $50-60 \%$ comprehension

- Frustration: Below 95\% word accuracy with any score for comprehension

In addition to the BAS, numerous other reading assessments utilize oral reading accuracy as an indicator of reading success and ability. While accuracy is certainly necessary to some extent for reading comprehension to take place, $100 \%$ accuracy during an oral reading experience is not. In fact, a misconception exists that implies comprehension automatically results from accurate reading. Accuracy models of assessment tend to ignore the fact that high-quality miscues do not prohibit readers' ability to understand what they read. According to Halladay (2012), "the paired criteria for decoding accuracy and comprehension rest on the assumption that the two standards will generally be achieved together. In other words, the reading levels assume that accurate oral reading and good comprehension typically go hand in hand" (p. 55). Additionally, Goodman (1996) asserts that "most readers self-correct only those miscues that are disruptive to reading and do not usually self-correct predictions that make sense as the reader is constructing meaningful text" (p. 602).

Many American teachers are mandated to assess students using a universal screener for reading proficiency. Students who do not meet benchmark criteria on these screeners are then assessed using an additional tool. Students are not ignorant to the fact that when they are pulled for more "tests" it means that they did not do something right the first time. Students who are assessed repeatedly tend to perceive themselves as having some sort of reading deficiency. "Struggling readers have been evaluated often and they believe that such experiences are to let them know what their problems are" (Goodman, 2008, p. 8). Miscue analysis coupled with Retrospective Miscue Analysis offers a chance to help these students perceive themselves as readers in a different way-focusing on what they do well as they read.

Miscue analysis, then, sits in contrast to the accuracy models of assessment described above. First, reading miscue analysis is grounded in the belief that students use multiple strategies simultaneously throughout the reading process. Therefore, in miscue analysis what would typically be considered an error in oral reading accuracy is termed a miscue instead. This is because the term error indicates a mistake that needs to be corrected, whereas miscue indicates that students are making meaning while reading texts. 
Miscue analysis is theoretically guided by psycholinguistic principles in that

Psycholinguistic Theory argues that readers use their knowledge about language, and the world in general, to drive their thinking as they engage in the reading process. The theory suggests that as they read, readers make predictions about what the text will say based on their knowledge in these areas. (Tracey \& Morrow, 2006, p. 58)

Within the Reading Miscue Inventory frame, all of the miscues made by a student during an oral reading event can be analyzed, allowing the teacher to code each in terms of syntactic and semantic acceptability. This information can be utilized when developing lessons tailored to the specific needs of an individual student or group of students. The information is also highly valuable when determining the benchmark reading level of students.

Retrospective Miscue Analysis (RMA) can function both as an assessment tool as well as an instructional approach. During RMA, teachers have the opportunity to share their analysis of a student's reading with the student. After teachers have analyzed their students' miscues from oral reading events and developed instruction based on this data, teachers can meet with students to discuss what they do while they read. Students revisit portions of the original oral reading experience to gain insight into the kinds of miscues they make while reading. This insight is usually very valuable to readers who teachers have labeled as "struggling," in that they are able to see that not all miscues during their reading should be considered unacceptable.

RMA sessions should not only include a discussion of student's miscues, but also a follow-up strategy lesson that is based on individual need. "For the purpose of informing instructional practice, the teacher may then look for patterns in these mismatches to disclose what readers know about... language cueing systems" (Moore \& Aspegren, 2001, p. 494). At times, teachers tend to teach reading strategy lessons to entire groups of students that may or may not need practice with that particular strategy. Handsfield and Jimenez (2009) point out that "different children may find different strategies useful at different times. To require that all students make connections at one moment negates these differences" (p. 179). Participation in and instruction using RMA virtually guarantees that students are receiving instruction in reading strategies that are relevant and worthwhile for them to learn and practice.

Further, "RMA research has proven that when readers talk about and reflect on their personal reading style there is a direct positive impact on reading ability" 
(Theurer, 2010, p. 63). RMA can work in a collaborative setting as well. During Collaborative Retrospective Miscue Analysis (CRMA), students work in small groups to help each other reason through miscues. A single student may volunteer to share a portion of his or her oral reading with the group while the others listen and follow along with the text. Goodman (1996) suggests that RMA "is especially supportive of students revaluing themselves when two or more readers participate" (p. 604). Through CRMA, students can take on the role of the teacher for each other, asking questions about what caused readers to make specific miscues in their reading and offering suggestions in a common language along the way.

\section{Setting the Context}

The school district in which Rebecca works mandates that all students be formally assessed for independent and instructional reading levels using the BAS (2011). Additionally, teachers must assess students with this tool three times throughout the school year. The data gathered from these assessments is analyzed at the school, grade, and district levels to help determine reading instructional strategies and groupings for students at all grade levels. The school and the district do not collect or analyze other data from teachers in their determination of a child's reading ability. The BAS requires teachers to view all miscues as errors and to code each error individually in order to obtain a word-reading accuracy score for each student.

Rebecca's school, Boyer Elementary School (pseudonym), is located in a Midwestern town of about 120,000 people. The town is primarily middle class and is the home to two universities. Boyer Elementary is a public school that serves kindergarten through fifth grade students. There are four class sections at each grade level and a population of around 650 students. Rebecca's fifth grade classroom served as the setting for the current study. Twenty-eight students participated, including 16 boys and 12 girls. Four students (three boys and one girl) have specific learning disabilities with individualized learning goals for reading and math. One female student in the class is gifted, and two other students (one boy and one girl) are currently applying to receive gifted education services. The cultural population of this class is $75 \%$ Caucasian, $11 \%$ African American, and $14 \%$ Asian.

During the six weeks of data collection, sources of information included the BAS assessments; marked typescripts of oral reading events and student retellings from selected readings; transcripts from whole-class, small-group, and individual 
discussions and strategy lessons; and field notes of observations from individual reading conferences and group discussions. Because BAS is the mandated assessment for the entire district, we chose to use this data as a baseline for students' reading ability as viewed by the district and school. Additionally, all these data forms allowed us to determine the validity of assessments whose primary focus is accuracy and speed. For the purposes of this study, validity refers to the degree to which data collected from a specific instrument supports any inferences the teacher or school administrator makes about a student's reading process. In other words, what is the appropriateness, meaningfulness, and usefulness of the specific inferences made based on the data the instrument provides (Fraenkel \& Wallen, 2000). Magnitude coding (Saldana, 2013) and a constant comparative method (Glaser \& Strauss, 1967) of data analysis were used throughout the study to observe and reflect on changes in students' view of reading and use of miscue vocabulary.

\section{Learning From Nate}

Our observations and reflection began with Nate. Nate provided a good example of a reader whose reading process was going unnoticed because of a lack of varied assessments. Nate was an above-average reader in Rebecca's class. Scores from previous years on the BAS indicated that his reading instructional level was slightly above grade level. To establish a baseline level, we chose a benchmarking text that was three levels above his previously assessed level. As Nate orally read the text, miscues were noted on a typescript. Nate read the nonfiction selection with appropriate fluency, paying attention to punctuation and phrasing. Along the way, Nate stopped several times to remark about a new fact he'd learned and make inferences about the text. At one point when the text described the high altitude at which China had built a railroad, Nate pondered, "I wonder how high up the highest railroad in North America is."

When Nate completed the oral reading portion of the assessment (about one-third of the length of the entire text), Rebecca asked him to finish reading the text silently. When he finished, Nate and Rebecca had a conversation about what Nate had read. He was able to give information about key details, provide his own interpretations of the text, and utilize the text to provide evidence for the statements he made. For example, Nate was able to use his background knowledge to determine that the permafrost on which the railroad was built related to permafrost that "gold miners in Alaska have to get through to get the gold" (Bowdish, 2008, p. 4). Nate earned a perfect ten out of a possible ten points on the comprehension portion of the assessment. However, Nate 
only read orally at a word-accuracy rate of $94 \%$. Regardless of Nate's perfect score on the comprehension portion of the assessment, his accuracy score placed the reading level assessed at frustration. This frustration level is what Rebecca is required to record and report to school administrators for Nate's reading ability, even though she knows he is a capable reader.

Using Nate's oral reading responses, we analyzed his accuracy percentage based upon high-quality miscues. That is, we went through the typescript with noted miscues and analyzed them to determine whether or not each miscue resulted in a loss of meaning. It was determined after controlling for high-quality miscues from Nate's oral reading that Nate read with $99 \%$ "accuracy," using high-quality substitutions, omissions, or insertions-with only $1 \%$ of his total miscues resulting in either partial or complete loss of meaning (this occurred when Nate substituted an unknown vocabulary word, "rivets," for a non-word, "rivities").

Our reflection of these data prompted us to assess the accuracy scores from the BAS for the other students in the class. We found that $68 \%$ of the class made high-quality miscues during oral reading that resulted in partial to no meaning loss. Table 1 reflects the analysis of the participants' word accuracy percentages and comprehension scores both before and after high-quality miscues were analyzed and removed from word accuracy percentage calculations.

\section{Table 1}

\section{John-Steiner's Four Patterns of Collaboration}

\begin{tabular}{|c|c|c|}
\hline STUDENT & $\begin{array}{l}\text { BEFORE Analysis of } \\
\text { High-Quality Miscues }\end{array}$ & $\begin{array}{l}\text { AFTER Analysis of } \\
\text { High-Quality Miscues }\end{array}$ \\
\hline Nate & $\begin{array}{l}\text { 94\% accuracy } \\
\text { 100\% comprehension } \\
\text { Reading level: Frustration }\end{array}$ & $\begin{array}{l}99 \% \text { accuracy } \\
100 \% \text { comprehension } \\
\text { Reading level: Independent }\end{array}$ \\
\hline Jack & $\begin{array}{l}94 \% \text { accuracy } \\
\text { 100\% comprehension } \\
\text { Reading level: Frustration }\end{array}$ & $\begin{array}{l}98 \% \text { accuracy } \\
\text { 100\% comprehension } \\
\text { Reading level: Independent }\end{array}$ \\
\hline Derek & $\begin{array}{l}96 \% \text { accuracy } \\
90 \% \text { comprehension } \\
\text { Reading level: Instructional }\end{array}$ & $\begin{array}{l}\text { 98\% accuracy } \\
\text { 90\% comprehension } \\
\text { Reading level: Independent }\end{array}$ \\
\hline Rebecca & $\begin{array}{l}98 \% \text { accuracy } \\
\text { 70\% comprehension } \\
\text { Reading level: Independent }\end{array}$ & $\begin{array}{l}100 \% \text { accuracy } \\
70 \% \text { comprehension } \\
\text { Reading level: Independent }\end{array}$ \\
\hline Ava & $\begin{array}{l}97 \% \text { accuracy } \\
80 \% \text { comprehension } \\
\text { Reading level: Instructional }\end{array}$ & $\begin{array}{l}99 \% \text { accuracy } \\
80 \% \text { comprehension } \\
\text { Reading level: Independent }\end{array}$ \\
\hline
\end{tabular}




\begin{tabular}{|c|c|c|}
\hline STUDENT & $\begin{array}{l}\text { BEFORE Analysis of } \\
\text { High-Quality Miscues }\end{array}$ & $\begin{array}{l}\text { AFTER Analysis of } \\
\text { High-Quality Miscues }\end{array}$ \\
\hline Madison & $\begin{array}{l}100 \% \text { accuracy } \\
50 \% \text { comprehension } \\
\text { Reading level: Instructional }\end{array}$ & N/A: No miscues to analyze \\
\hline Rajvir & $\begin{array}{l}95 \% \text { accuracy } \\
80 \% \text { comprehension } \\
\text { Reading level: Instructional }\end{array}$ & $\begin{array}{l}98 \% \text { accuracy } \\
80 \% \text { comprehension } \\
\text { Reading level: Independent }\end{array}$ \\
\hline Rachel & $\begin{array}{l}96 \% \text { accuracy } \\
80 \% \text { comprehension } \\
\text { Reading level: Instructional }\end{array}$ & $\begin{array}{l}98 \% \text { accuracy } \\
80 \% \text { comprehension } \\
\text { Reading level: Independent }\end{array}$ \\
\hline Heather & $\begin{array}{l}96 \% \text { accuracy } \\
80 \% \text { comprehension } \\
\text { Reading level: Instructional }\end{array}$ & $\begin{array}{l}98 \% \text { accuracy } \\
80 \% \text { comprehension } \\
\text { Reading level: Independent }\end{array}$ \\
\hline Andrea & $\begin{array}{l}96 \% \text { accuracy } \\
90 \% \text { comprehension } \\
\text { Reading level: Instructional }\end{array}$ & $\begin{array}{l}\text { 98\% accuracy } \\
\text { 90\% comprehension } \\
\text { Reading level: Independent }\end{array}$ \\
\hline Miranda & $\begin{array}{l}97 \% \text { accuracy } \\
70 \% \text { comprehension } \\
\text { Reading level: Instructional }\end{array}$ & $\begin{array}{l}\text { 99\% accuracy } \\
\text { 70\% comprehension } \\
\text { Reading level: Independent }\end{array}$ \\
\hline Chris & $\begin{array}{l}96 \% \text { accuracy } \\
80 \% \text { comprehension } \\
\text { Reading level: Instructional }\end{array}$ & $\begin{array}{l}98 \% \text { accuracy } \\
80 \% \text { comprehension } \\
\text { Reading level: Independent }\end{array}$ \\
\hline Alex & $\begin{array}{l}97 \% \text { accuracy } \\
60 \% \text { comprehension } \\
\text { Reading level: Frustration }\end{array}$ & $\begin{array}{l}98 \% \text { accuracy } \\
60 \% \text { comprehension } \\
\text { Reading level: Instructional }\end{array}$ \\
\hline Michael & $\begin{array}{l}96 \% \text { accuracy } \\
70 \% \text { comprehension } \\
\text { Reading level: Instructional }\end{array}$ & $\begin{array}{l}98 \% \text { accuracy } \\
70 \% \text { comprehension } \\
\text { Reading level: Independent }\end{array}$ \\
\hline Jake & $\begin{array}{l}\text { 97\% accuracy } \\
\text { 90\% comprehension } \\
\text { Reading level: Instructional }\end{array}$ & $\begin{array}{l}\text { 98\% accuracy } \\
\text { 90\% comprehension } \\
\text { Reading level: Independent }\end{array}$ \\
\hline Meredith & $\begin{array}{l}98 \% \text { accuracy } \\
70 \% \text { comprehension } \\
\text { Reading level: Instructional }\end{array}$ & $\begin{array}{l}\text { 99\% accuracy } \\
\text { 70\% comprehension } \\
\text { Reading level: Independent }\end{array}$ \\
\hline Dustin & $\begin{array}{l}96 \% \text { accuracy } \\
80 \% \text { comprehension } \\
\text { Reading level: Instructional }\end{array}$ & $\begin{array}{l}98 \% \text { accuracy } \\
80 \% \text { comprehension } \\
\text { Reading level: Independent }\end{array}$ \\
\hline Elizabeth & $\begin{array}{l}96 \% \text { accuracy } \\
50 \% \text { comprehension } \\
\text { Reading level: Frustration }\end{array}$ & $\begin{array}{l}98 \% \text { accuracy } \\
50 \% \text { comprehension } \\
\text { Reading level: Instructional }\end{array}$ \\
\hline Amelia & $\begin{array}{l}96 \% \text { accuracy } \\
90 \% \text { comprehension } \\
\text { Reading level: Instructional }\end{array}$ & $\begin{array}{l}\text { 98\% accuracy } \\
\text { 90\% comprehension } \\
\text { Reading level: Independent }\end{array}$ \\
\hline Connor & $\begin{array}{l}97 \% \text { accuracy } \\
70 \% \text { comprehension } \\
\text { Reading level: Instructional }\end{array}$ & $\begin{array}{l}\text { 99\% accuracy } \\
\text { 70\% comprehension } \\
\text { Reading level: Independent }\end{array}$ \\
\hline
\end{tabular}




\begin{tabular}{|c|c|c|}
\hline STUDENT & $\begin{array}{l}\text { BEFORE Analysis of } \\
\text { High-Quality Miscues }\end{array}$ & $\begin{array}{l}\text { AFTER Analysis of } \\
\text { High-Quality Miscues }\end{array}$ \\
\hline Laura & $\begin{array}{l}97 \% \text { accuracy } \\
70 \% \text { comprehension } \\
\text { Reading level: Instructional }\end{array}$ & $\begin{array}{l}99 \% \text { accuracy } \\
70 \% \text { comprehension } \\
\text { Reading level: Independent }\end{array}$ \\
\hline Brandon & $\begin{array}{l}97 \% \text { accuracy } \\
70 \% \text { comprehension } \\
\text { Reading level: Instructional }\end{array}$ & N/A: Analysis resulted in no change \\
\hline Cindy & $\begin{array}{l}97 \% \text { accuracy } \\
80 \% \text { comprehension } \\
\text { Reading level: Instructional }\end{array}$ & N/A: Analysis resulted in no change \\
\hline Nick & $\begin{array}{l}99 \% \text { accuracy } \\
50 \% \text { comprehension } \\
\text { Reading level: Instructional }\end{array}$ & N/A: Analysis resulted in no change \\
\hline Matt & $\begin{array}{l}97 \% \text { accuracy } \\
70 \% \text { comprehension } \\
\text { Reading level: Instructional }\end{array}$ & N/A: Analysis resulted in no change \\
\hline Andy & $\begin{array}{l}99 \% \text { accuracy } \\
60 \% \text { comprehension } \\
\text { Reading level: Instructional }\end{array}$ & N/A: Analysis resulted in no change \\
\hline Zach & $\begin{array}{l}97 \% \text { accuracy } \\
80 \% \text { comprehension } \\
\text { Reading level: Instructional }\end{array}$ & N/A: Analysis resulted in no change \\
\hline Chad & $\begin{array}{l}99 \% \text { accuracy } \\
60 \% \text { comprehension } \\
\text { Reading level: Instructional }\end{array}$ & $\mathrm{N} / \mathrm{A}$ : Analysis resulted in no change \\
\hline
\end{tabular}

While comparing these two sets of data, we noticed that a student scoring $94 \%$ on word-accuracy and $100 \%$ on comprehension is considered frustrated at the assessed reading level in the BAS system for grades 3-8. However, a student who reads with $100 \%$ word accuracy but only scores $50 \%$ for comprehension is determined to be reading at an instructional level. We also noticed that $68 \%$ of the students would actually be considered at a higher reading level (independent or instructional) if Rebecca were allowed to control for high-quality miscues before reporting their scores to the district. Finally, in our ongoing reflection and discussion, we felt that the most problematic observation from these data was that readers like Nate, Jack, and Alex were considered frustrated readers. However, we considered them to be among the strongest readers in the class.

With the mandated assessment, we knew that the readers in Rebecca's class might be learning that accuracy was more important than comprehension. We also knew that we wanted students to learn the difference between low- and high-quality miscues to make learning more purposeful. 


\section{Building a Culture of Meaning Making: Learning From Each Other}

After coming to the realization that students in Rebecca's class may be placing a higher value on reading with $100 \%$ word accuracy rather than on comprehension, we focused our instructional efforts on changing the culture of reading in her classroom. To alter the perception that good reading is perfect reading, we decided to explicitly instruct Rebecca's students in the language of miscue analysis, so that they could begin to value their own strengths as readers.

\section{Whole-Group Instruction}

We began this process of changing the culture through whole-group instruction. Rebecca focused mini-lessons on defining the terms "miscue," "substitution," "omission," and "high quality" to give students a vocabulary to describe more precisely what they were doing as readers. She displayed examples of students' typescripts on the white board and explained how each was marked to show what the text said and the response the reader gave. The purpose of these initial examples was to keep things simple at the start with high-quality miscues until the students understood some of the terms. Two of these examples follow.

\section{the}

- But now a new phenomenon breaches the isolation of this rugged terrain.

\section{The}

- Its outermost layer is called the crust and is made up of huge sections...

As a whole class, they discussed the differences between the readers' responses and the text and determined together whether or not the miscues disrupted the reader's ability to make meaning from the text:

Rebecca: Why did the student substitute the words "this" and "its" for "the" in these sentences?

Ava: Well, it didn't really matter if they said "this" or "its" because it still makes sense with "the."

Rebecca: That's right! They're high-quality miscues because they don't mess up your comprehension. 
After talking through several examples of high-quality miscues during the previous lesson, Rebecca developed mini-lessons to present examples of high-quality miscues that did not need correction but the reader corrected anyway. In some examples that were presented, the reader substituted an acceptable word within the sentence and self-corrected the miscue, as in the example below.

\section{giant (self-correction) \\ gigantic (first response)}

- The International Space Station, or ISS, is a giant research facility now being assembled...

- ...they have to examine the potential impact on humans, both physically and psychologically, of living in a space station (Kees, 2008)

\section{a \\ the}

When Rebecca asked why students thought that they needed to correct a miscue that clearly didn't change the meaning of the text, Mandy responded, "Because you get a bad grade if you don't read all the words right." At this point, Rebecca was able to compare the students' previous discussion about the necessity of correcting miscues that do not disrupt meaning.

Throughout the weeks that followed, Rebecca invited students to discuss highquality miscues that she unintentionally made while reading aloud to the class in order to analyze them for quality-did the miscue need to be corrected or not. Students used a shared vocabulary to talk about why Rebecca read contractions such as "wasn't" when the expected response from the text was "was not." This began to happen so frequently within Rebecca's read-aloud events that after one week of having students call out miscues, she had them indicate them on sticky notes to discuss when the read aloud was finished.

Occasionally, Rebecca intentionally made miscues that disrupted the meaning of the text she was reading aloud to her students. Conversations focused on the information students used to determine whether these miscues were acceptable or not. Students were able to identify the exact words that disrupted comprehension and were able to supply alternative words to correct the low-quality miscue. 


\section{Individual Instruction}

After some initial whole-group instruction, Rebecca began to simultaneously instruct each of the students in the language of analyzing miscues for acceptability and quality. She met with students one on one during regular reading conferences to discuss their oral reading. During these meetings, students read aloud from selfselected books or guided reading books that had been previously assigned to them. She used the In-Process Comprehension Rubric (Wedwick \& Urbanc, 2012) (see Figure 1) to analyze their reading, rather than complete a traditional running record. This rubric allows teachers to listen for miscues that result in a loss of meaning. By using this tool during reading conferences with her students, she was able to provide instant feedback about what they were doing as readers and direct strategy instruction based on their needs. At the same time, she was able to refer to the whole-group mini-lessons and use consistent vocabulary with students regarding their miscues.

\section{In-Process Comprehension Rubric}

Reader:

Date:

Grade

Title:

Does the sentence make sense the way the reader left it?

Yes

Total

No

Total

Number of Sentences Read

Comprehension Score

Divide total Yes by total number of sentences for Comprehension Score. 


\begin{tabular}{|c|c|c|c|c|}
\hline & $\begin{array}{c}\text { Beginning } \\
1\end{array}$ & $\begin{array}{c}\text { Developing } \\
2\end{array}$ & $\begin{array}{c}\text { Transitioning } \\
3\end{array}$ & $\begin{array}{c}\text { Confident } \\
4\end{array}$ \\
\hline Phrasing & $\begin{array}{l}\text { Monotonic } \\
\text { with little } \\
\text { sense of phrase } \\
\text { boundaries, } \\
\text { frequent } \\
\text { word-by-word } \\
\text { reading. }\end{array}$ & $\begin{array}{l}\text { Frequent short } \\
\text { word phrases, } \\
\text { choppy reading; } \\
\text { improper stress } \\
\text { and intonation } \\
\text { that fail to } \\
\text { mark ends of } \\
\text { sentences. }\end{array}$ & $\begin{array}{l}\text { Mixture of } \\
\text { run-ons, mid } \\
\text { sentence } \\
\text { pauses, and } \\
\text { possibly some } \\
\text { choppiness; } \\
\text { reasonable } \\
\text { stress/ } \\
\text { intonation }\end{array}$ & $\begin{array}{l}\text { Generally well } \\
\text { phrased, mostly } \\
\text { in clause and } \\
\text { sentence units, } \\
\text { with adequate } \\
\text { attention to } \\
\text { expression. }\end{array}$ \\
\hline Intonation & $\begin{array}{l}\text { Monotonic } \\
\text { reading. }\end{array}$ & $\begin{array}{l}\text { Some changes } \\
\text { in voice pitch/ } \\
\text { expression } \\
\text { that may not } \\
\text { match the text } \\
\text { meaning. }\end{array}$ & $\begin{array}{l}\text { Appropriate } \\
\text { changes in voice } \\
\text { pitch/expression } \\
\text { that reflect } \\
\text { comprehension } \\
\text { of text. }\end{array}$ & $\begin{array}{l}\text { Appropriate } \\
\text { changes in voice } \\
\text { pitch/expression } \\
\text { that reflect } \\
\text { comprehension } \\
\text { of text and } \\
\text { add dramatic } \\
\text { emphasis. }\end{array}$ \\
\hline $\begin{array}{r}\text { Miscues } \\
\text { Omissions, } \\
\text { Insertions, \& } \\
\text { Substitutions }\end{array}$ & $\begin{array}{l}\text { Low quality } \\
\text { miscues leading } \\
\text { to a complete } \\
\text { breakdown of } \\
\text { comprehension. }\end{array}$ & $\begin{array}{l}\text { Mostly low } \\
\text { quality miscues } \\
\text { that usually } \\
\text { prohibit } \\
\text { comprehension. }\end{array}$ & $\begin{array}{l}\text { Inconsistent use } \\
\text { of high and low } \\
\text { quality miscues. }\end{array}$ & $\begin{array}{l}\text { Mostly high } \\
\text { quality miscues } \\
\text { that show } \\
\text { confidence in } \\
\text { properly editing } \\
\text { the text }\end{array}$ \\
\hline $\begin{array}{r}\text { Self } \\
\text { Monitoring \& } \\
\text { Correcting }\end{array}$ & $\begin{array}{l}\text { Low quality } \\
\text { miscues are not } \\
\text { corrected }\end{array}$ & $\begin{array}{l}\text { Inconsistent use } \\
\text { of correction } \\
\text { when necessary } \\
\text { for making } \\
\text { sense. }\end{array}$ & $\begin{array}{l}\text { Uses correction } \\
\text { but may not } \\
\text { recognize when } \\
\text { it's necessary } \\
\text { and when it's an } \\
\text { overcorrection. }\end{array}$ & $\begin{array}{l}\text { Consistently } \\
\text { corrects only } \\
\text { low quality } \\
\text { miscues. }\end{array}$ \\
\hline Retell & $\begin{array}{l}\text { Fragmented } \\
\text { and disjointed } \\
\text { even with } \\
\text { probing and } \\
\text { questioning. }\end{array}$ & $\begin{array}{l}\text { General retell } \\
\text { with probes } \\
\text { and questions, } \\
\text { details and } \\
\text { personal } \\
\text { interpretation. }\end{array}$ & $\begin{array}{l}\text { Acceptable } \\
\text { retell with } \\
\text { details and } \\
\text { some personal } \\
\text { interpretations. }\end{array}$ & $\begin{array}{l}\text { Highly } \\
\text { independent } \\
\text { retell with } \\
\text { details and } \\
\text { high levels } \\
\text { of personal } \\
\text { interpretation }\end{array}$ \\
\hline
\end{tabular}

Fig. 1: Wedwick, L. \& Urbanc, S. (2012). Assessment and instruction in reading in an RTI classroom. In Bakken, J. P. (Ed.). Response to intervention in the core content areas: A practical approach for educators (pp. 145-166). Waco, TX: Prufrock Press. 
Much of the one-on-one discussion between Rebecca and her students focused on meaning-making during reading, as well as the conscious act of monitoring understanding throughout reading. While students were easily able to monitor comprehension while listening to Rebecca or their peers read aloud, data acquired by using the In-Process Comprehension Rubric revealed that some students were not consistently monitoring comprehension during their own experiences reading aloud. During one-on-one conferences, conversations began to focus on explicit instruction of monitoring comprehension during reading. Rebecca tracked students' comprehension and meaning-making during the reading process and used that information to immediately show students what they were doing while reading. Rebecca met with students who were struggling with monitoring their comprehension two to three times per week. At each meeting, she collected information about students' reading on the In-Process Comprehension Rubric and used the data to instruct and set goals with these students. All of the data was kept in Rebecca's reading conference binder. We observed improvement in the comprehension monitoring skills of these students throughout the course of this study based on improved scores on the In-Process Comprehension Rubric.

\section{Small-Group Instruction}

Students continued to participate in regular reading activities such as book clubs and small-group discussions throughout this study. While observing students' reading discussions during book clubs, we noted that when students orally shared portions of texts they were unlikely to correct miscues that did not disrupt meaning. Additionally, students were more actively engaged in listening and following along as their peers read aloud sections of their novels. This was evident during discussions when students pointed out low-quality miscues to each other and asked their peers to reread. Students also began praising their peers for not correcting high-quality miscues during these shared reading times.

During one small-group meeting, five students seated around a table, who would likely be described as "struggling readers" by some teachers because they were not meeting grade level expectations on district-mandated reading assessments, engaged in a conversation that was not led by the teacher. The students fluently and accurately discussed "miscues" made during their oral reading. They described their choices when they made "miscues" and seemed to be using a shared vocabulary in which they explained their predictions and the acceptability of their miscues. We took notes and observed as the small group continued to discuss Jack's use of the word "mom" rather than the expected response of "mother" during his oral reading. 
Alex: I think that's an acceptable miscue. It's high quality.

Elizabeth: Why?

Alex: Because "mom" means the same thing as "mother." "Mother" is not a word I would normally use every day. I would say "mom" instead. Plus, I can still tell you what the text means. It didn't change any meanings.

Elizabeth: You know, I think you're right. "Mom" is an okay thing to say there. It's acceptable.

These students have been instructed not to look upon the inaccuracies they make during their oral reading as errors, but rather as miscues. They have learned the vocabulary that is necessary to effectively and efficiently explain how they monitored their comprehension during reading.

\section{Small-Group Instruction Extension-Cloze Procedure}

Based on the data collected during independent reading conferences and an analysis of the In-Process Comprehension Rubric, we could easily recognize that a handful of students in Rebecca's class were consistently making miscues that demonstrated only partial semantic or syntactic acceptability. That is, students were making miscues in their reading that made sense either up to and including the miscue, or from the miscue to the end of the sentence, such as the example below.

\section{when the}

- Scientists describe the seismograph's measurements with numbers (Herenger, 2008).

While the response of "when the" for "with" is not completely semantically or syntactically acceptable for the entire sentence, it maintains acceptability up to and including the miscue. It would make sense for the sentence to say, "Scientists describe the seismograph's measurements when the," and then go on to state when scientists describe the seismograph's measurements. In another example, the substitution of "in advance" for "is evidence" still maintains partial semantic and syntactic acceptability because the phrase "in advance of a major earthquake" could make sense in a different context. 
- Earthquakes over 5.0 on the scale can cause damage, while a measurement of 7.0 is evidence of a major earthquake (Herenger, 2008). in advance

Because several of the students made these similar kinds of miscues in their oral reading, we wanted to try a different approach to evaluate choices they were making during reading. Linda had previously used a process similar to a cloze procedure, such as "The Reading Detective Club" by Debra Goodman (1999), to help students evaluate their word choices. Therefore, we flexibly grouped students based on similarities of their miscues to engage in a series of cloze activities. During a cloze activity, students are asked to fill in a blank within a sentence in the context of a full narrative. "A cloze differs from a 'fill in the blank' exercise comprised of isolated sentences in that it is a method applied to a passage, and is therefore contextualized" (Steinman, 2002, p. 291). Students must read the entire sentence and passage to select words that are missing from the selection. We were curious to find out if students who consistently made only miscues that were partially semantically and/or syntactically acceptable during oral reading would also choose words in the cloze activity that were similarly partially acceptable. Rebecca met with each of five students individually to explain the cloze procedure and how to complete the activity (see Figure 2). Students completed the cloze activity independently, and we analyzed their responses in a small group for semantic and syntactic acceptability. 


\section{Cloze Procedure}

Name Date

LANGUAGE ARTS ACTIVITY - Cloze

READ THE STORY BELOW. SOME OF THE WORDS HAVE BEEN LEFT OUT ON PURPOSE. FILL IN THE BLANKS THAT WILL MAKE THE STORY MAKE SENSE.

Gwendolyn and Sharrie were about to take the test of their lives. It was a long test and they had to be able to divide a 4 digit by 1 digit number. of them had been working hard on this skill. Gwendolyn was in Math and Sharrie was at reading and writing skills.

Their Mrs. Lawton had worked very to teach them this math skill.

Gwendolyn was she knew how to do the problems

Sharrie was a little and hoped she could remember each step. Mrs. Lawton out the test and everyone was very Gwendolyn smiled at Sharrie and whispered " " Sharrie back at her and went to on her test. The children had thirty to complete the fifteen . Everyone was quiet and were on doing their best

Soon Mrs. took up the test papers and told everyone to take a fifteen minute She would the papers while they were gone. Mrs. Lawson came outside and called the students the classroom. She had a big on her face and started to call each student's to pick up their papers. Sharrie's name was third.

She went to It was an her paper and looked down at the and a comment was

Sharrie could not believe she had her paper from Mrs. Lawson. There at the slowly up to . Gwendolyn almost all the way back to her

She knew she was at division, she just couldn't believe she didn't miss a single problem. School was for the of the day.

Fig. 2: Example of a cloze passage used to determine students' use of semantically and syntactically acceptable substitutions

As it turned out, each of the five students who completed the cloze activity demonstrated a similar pattern of substituting partially semantically and syntactically acceptable words in at least two of their responses. Below are examples of students' responses that demonstrate partial semantic and syntactic acceptability (words and phrases supplied by students are underlined): 
- Sharrie turned back at her.

- Mrs. Lawton passed out the test and everyone was very nice.

- She went to get her paper and looked down at the test on the top of her paper.

- Gwendolyn almost dropped all the way back to her seat.

- Sharrie smiled back at her and went to take on her test.

- She walked slowly up to the teacher her paper from Mrs. Lawton.

Obviously, students used prediction strategies to fill in blanks. However, they were clearly not actively monitoring comprehension throughout the entire passage. This group of students participated in a CRMA focusing specifically on those miscues that resulted in only partial semantic or syntactic acceptability:

Rebecca: I noticed that lots of you were doing the same things as you read. You're making good choices, but you're only reading part of a sentence and filling in a blank. It's making sense up to that part, but not all the way through the whole sentence. Can you find an instance on your sheet where you did that?

Chris: I put, "She went to pick her paper and looked down at the grade."

Rachel: Why did you pick the word pick, Chris?

Chris: I think I probably meant "pick up."

Ava: I did one that said, "Gwendolyn almost got all the way back to her eyes."

Jack: Well, we could say, "Gwendolyn almost got all the way back," and that would make sense! But, eyes? That doesn't work. Why did you pick eyes?

Rachel: I think she picked eyes because maybe it's because her eyes were looking at the $A$.

Ava: Yeah! Her eyes were looking at the A. 


\section{What Did We Learn?}

Based on all of the instruction surrounding miscue analysis that happened in Rebecca's classroom, we learned that students could benefit from explicit instruction in the language of miscue analysis. We learned that students could learn and use the vocabulary of a reading process focused on comprehension rather than word accuracy. We learned that students could actively monitor comprehension while reading by recognizing whether a miscue was high or low quality. We learned that a vast majority of the students in Rebecca's class were more capable readers than the mandated assessment suggested.

By listening to discussions that students had during small-group meetings, in book clubs, and in one-on-one reading conferences, we began to notice a shift in the reading culture of this group of students. Students began to listen for meaning, rather than mistakes during oral reading events. They were actively discussing whether or not substitutions, omissions, or insertions during reading were acceptable based upon whether or not they disrupted comprehension, rather than on whether the exact words were found in the text. Students began to understand that the most important aspect of reading is comprehension, not accuracy of oral reading.

Finally, we learned the value of engaging in action research to improve one's practice. It was through systematic observation and the subsequent reflection of these data that guided Rebecca's instructional decisions. Cochran-Smith and Lytle (1993) define teacher research as intentional, systematic inquiry that helps to privilege the teacher's voice and point of view (Pappas \& Tucker-Raymond, 2011). For Rebecca, engaging in a cycle of observation, reflection, and action allowed her to trust her professional judgment and to develop a habit of inquiry.

\section{Where Do We Go From Here?}

By virtue of being a self-contained elementary classroom teacher, one-on-one time to complete traditional in-depth Reading Miscue Inventory was limited. We elected to use data gleaned from the BAS because we were concerned about having enough instructional time to collect adequate data on students to analyze for our action research since the school was mandating this particular assessment system. However, we believe that the use of the mandated benchmark assessment for analysis in our 
research provided us with valuable insights, along with the other assessments we used, into determining the actual instructional and independent reading levels for each of the students. This inquiry experience allowed Rebecca to value the importance of varied assessments when helping students improve their learning.

Further, even though Rebecca firmly believes in the consideration of high-quality miscues when calculating a student's word accuracy after an oral reading event, this doesn't mean that her school district will consider alternative and varied assessments to monitor students' progress. She is mandated to administer the district-wide assessment and to strictly follow the criteria for scoring these assessments as set forth by the publishers, which leaves very little, if any, room for her professional judgment. She, as well as other teachers in her district, is limited in making final benchmark leveling decisions based on her knowledge of students' reading miscues until her school district is exposed to the value of analyzing them.

The time limitations for this research study impacted our ability to recognize the long-term effects of Retrospective Miscue Analysis strategy instruction on reading comprehension and ability within a fifth grade classroom. While in the short term we were able to gain insight into Rebecca's students' thinking as readers, we were unable to ascertain whether RMA strategies will have long-term effects on the reading competency of the students. More practice and data collection are necessary to make generalizations about students' long-term reading growth based on these instructional strategies.

At the outset of this journey, we wanted to know if we could change the culture of an accuracy view of reading to one of comprehension. We approached this process through a series of whole-group, small-group, and individualized instruction. The goal was to establish a common vocabulary and to revalue the process of reading and the smart choices that readers make as they read. One of the most obvious influences for how teachers and students view the process of reading is the way in which some assessment systems value reading. We believe that Rebecca's school and district are similar to many other districts that use only one assessment to determine a student's instructional and independent reading levels and that consider word-reading accuracy the key factor of a student's reading competency.

As educators, we need to be sure to place value on our own professional knowledge of the abilities of each of our students. If we blindly follow the guidelines for reading levels that place a heavy emphasis on word accuracy in oral reading, we are not only doing a disservice to our students by not challenging them with texts that they 
can ultimately read with a high degree of comprehension, but we are also missing out on opportunities to provide skill-specific instruction for individual students. Benchmark leveling systems provide these guidelines with which to judge our students in addition to our own professional knowledge, not instead of it. It is our fervent hope that students make miscues during reading. This way, educators will gain valuable insight into the cognitive functions that their students are using during oral reading.

Throughout this research study, Rebecca and her students were able to begin and carry on a dialogue about what they were actually doing as readers. Discussion about acceptable versus not acceptable miscues in oral reading took place on a daily basis as she met with small groups to discuss their strengths, conferenced with individuals and gave immediate feedback to students while listening to their reading, and instructed her readers in the language of miscue analysis.

What matters more in reading instruction of students: accuracy or comprehension? The goal of reading is to understand text, not to recite the perfect pronunciation of every single word on a page. Why, then, do some students believe that the expectation is perfect accuracy in an oral reading event? Why do some students believe that good readers know all the words? We encourage administrators to trust teachers' professional judgment to look beyond the assessment numbers - to allow an analysis of all data that informs teachers when determining the strengths and weaknesses of students' reading strategies. At the same time, we encourage teachers to not blindly follow the cut scores for independent and instructional reading levels. Instead, use the information that you have spent time collecting about your students to design meaningful instruction based upon the needs of your individual learners. You know them better than any publisher. Provide them with the reading instruction that you know they deserve.

\section{References}

Betts, E.A. (1946). Foundations of reading instruction, with emphasis on differentiated guidance. New York: American Book.

Bowdish, L. (2008). The train at the top of the world. Portsmouth: Heinemann.

Cochran-Smith, M., \& Lytle, S.L. (1993). Inside/outside: Teacher research and knowledge. New York: Teachers College Press.
Fountas, G.S., \& Pinnell, I.C. (2011). Assessment guide: A guide to benchmark assessment system 2. Portsmouth: Heinemann.

Fraenkel, J.R., \& Wallen, N.E. (2000). How to design \& evaluate research in education. Boston: McGraw Hill.

Glaser, B., \& Strauss, A. (1967). The discovery of grounded theory: Strategies for qualitative research. New York: Aldine de Gruyter. 
Goodman, D. (1999). The reading detective club: Solving the mysteries of reading. Portsmouth: Heinemann.

Goodman, Y.M. (1996). Revaluing readers while readers revalue themselves: Retrospective miscue analysis. The Reading Teacher, 49(8), 600-609.

Goodman, Y.M. (2008). Retrospective miscue analysis: An overview. Retrieved from: http://www.rcowen.com/WordDocs/RMAOverviewChapter.doc

Halladay, J.L. (2012). Revisiting key assumptions of the reading level framework. The Reading Teacher, 66(1), 53-62.

Handsfield, L.J., \& Jimenez, R.T. (2009). Cognition and misrecognition: A Bourdieuian analysis of cognitive strategy instruction in a linguistically and culturally diverse classroom. Journal of Literacy Research, 41(2), 151-190.

Herenger, K. (2008). Earthquakes. Portsmouth: Heinemann.

Kees, M. (2008). The international space station. Portsmouth: Heinemann.

Moore, R.A., \& Aspegren, C.M. (2001). Reflective conversations between two learners: Retrospective miscue analysis. Journal of Adolescent \& Adult Literacy, 44(6), 492-503.
Pappas, C.C., \& Tucker-Raymond, E. (2011). Becoming a teacher researcher in literacy teaching and learning: Strategies and tools for the inquiry process. New York: Routledge.

Saldana, J. (2013). The coding manual for qualitative researchers. Thousand Oaks, CA: Sage.

Steinman, L. (2002). Considering the cloze. The Canadian Modern Language Review, 59(2), 291-301.

Theurer, J.L. (2010). Retrospective miscue analysis and the socialization of one young adult reader. Journal of Instructional Psychology, $37(1), 63-70$.

Theurer, J.L. (2011). Does accuracy make a difference? Examining the miscues of proficient and less than proficient adult readers. Literacy Research and Instruction, 50(3), 173-182.

Tracey, D.H., \& Morrow, L.M. (2006). Lenses on reading: An introduction to theories and models. New York: The Guilford Press.

Wedwick, L., \& Urbanc, S. (2012). Assessment and instruction in reading in an RTI classroom. In Bakken, J. P. (Ed.). Response to intervention in the core content areas: A practical approach for educators (pp. 145-166). Waco, TX: Prufrock Press. 


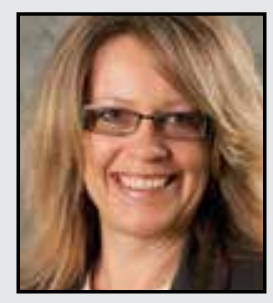

Linda Haling is an Associate Professor and Coordinator of Graduate Studies for the School of Teaching and Learning at Illinois State University. She currently teaches both graduate and undergraduate courses in assessment and early adolescent literacy learning. Linda is a former middle school teacher and reading specialist. She has extensively researched self-selection of books and adolescent literature. She is the recipient of the Clarence W. Sorensen Distinguished Dissertation Award and the Mary S. Arnold Research Award. She has authored book chapters in addition to articles that have appeared in The Reading Teacher and Voices from the Middle. She is co-author of BOOKMATCH: How to Scaffold Student Book Selection for Independent Reading, published by the International Reading Association.

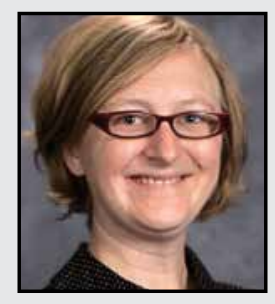

Rebecca Spears is passionate about researching and implementing best practice reading instruction in her classroom. She has her master's degree in Reading from Illinois State University. She is currently involved in helping to transition her school district to a standards-based grading reporting format, and is working to develop rubrics for teachers and students to use in assessment of reading and language arts skills. Rebecca has 12 years of teaching experience at the first, fourth, fifth, seventh, and eighth grade levels in both urban and suburban school districts. She has served on multiple literacy task forces, and presented at district-wide institutes. 